OPEN ACCESS

Edited by: Maristella Maggi, University of Pavia, Italy

Reviewed by:

Carlo Ganini,

University of Rome Tor Vergata, Italy

Jan Styczynski,

University of Bydgoszcz, Poland

*Correspondence:

Mahmood Hachim

Mahmood.AIMashhadani@mbru.ac.ae

Specialty section:

This article was submitted to

Molecular Medicine,

a section of the journal

Frontiers in Cell and Developmental

Biology

Received: 06 May 2021

Accepted: 03 June 2021

Published: 25 June 2021

Citation:

Alsuwaidi L, Hachim M and

Senok A (2021) Novel Markers

in Pediatric Acute Lymphoid Leukemia: The Role of ADAM6 in B

Cell Leukemia.

Front. Cell Dev. Biol. 9:706129. doi: 10.3389/fcell.2021.706129

\section{Novel Markers in Pediatric Acute Lymphoid Leukemia: The Role of ADAM6 in B Cell Leukemia}

\author{
Laila Alsuwaidi', Mahmood Hachim ${ }^{1,2 *}$ and Abiola Senok ${ }^{1}$ \\ ${ }^{1}$ College of Medicine, Mohammed Bin Rashid University of Medicine and Health Sciences, Dubai, United Arab Emirates, \\ ${ }^{2}$ Center for Genomic Discovery, Mohammed Bin Rashid University of Medicine and Health Sciences, Dubai, United Arab \\ Emirates
}

Background: The extensive genetic heterogeneity found in the B cell precursor acute lymphoblastic leukemia (BCP-ALL) subtype of childhood ALL represents a potential repository of biomarkers. To explore this potential, we have carried out in silico analysis of publicly available ALL datasets to identify genetic biomarkers for childhood BCP-ALL, which could be used either individually or in combination as markers for early detection, risk stratification, and prognosis.

Methods: To explore novel genes that show promising clinical and molecular signatures, we examined the cBioPortal online tool for publicly available datasets on lymphoid cancers. Three studies on lymphoblastic and lymphoid leukemia with 1706 patients and 2144 samples of which were identified. Only B-Lymphoblastic Leukemia/Lymphoma samples $(n=1978)$ were selected for further analysis. Chromosomal changes were assessed to determine novel genomic loci to analyze clinical and molecular profiles for the leukemia of lymphoid origin using cBioPortal tool.

Results: ADAM6 gene homozygous deletions (HOM:DEL) were present in 59.60\% of the profiled patients and were associated with poor ten years of overall patients' survival. Moreover, patients with ADAM6 HOM:DEL showed a distinguished clinical and molecular profile with higher Central Nervous System (CNS) sites of relapse. In addition, ADAM6 HOM:DEL was significantly associated with unique microRNAs gene expression patterns.

Conclusion: ADAM6 has the potential to be a novel biomarker for the development and progress of BCP- ALL.

Keywords: ADAM6, acute lymphoid leukemia, bioinformactics analysis, biomarkers, pediatric leukemia

\section{BACKGROUND}

Acute lymphoblastic leukemia (ALL) is a clonal expansion of abnormal lymphoid progenitors of $\mathrm{B}$ cell or T cell origin, eventually invading the bone marrow and peripheral blood (Pastorczak et al., 2021). ALL is the most common malignancy in the pediatric age group accounting for $26 \%$ of childhood and adolescent cancers (Ward et al., 2014). Although ALL develops in children and adults, the peak incidence is in those aged 1-4 years (Malard and Mohty, 2020). 
Some cases of pediatric acute leukemias that can be diagnosed in children under one year of age are characterized by unique and aggressive biology (Ibrahimova et al., 2021). On the other hand, $60 \%$ of ALL are diagnosed before the age of 20 years (Giddings et al., 2016; Howlader et al., 2021). It represents a significant health concern globally as a major cause of childhood cancer-related mortality affecting children and young adults in their prime age (Starý and Hrušák, 2016; Zapata-Tarrés et al., 2021). From 1975-2012, ALL incidence increased by $0.8 \%$ per year in the United States to reach 15.7 cases for every $10^{6}$ persons, with approximately 5,970 new cases and 1,440 deaths in 2017 (Siegel et al., 2016).

The B cell precursor ALL (BCP-ALL) is a subtype of childhood ALL with a suggested multi-factorial etiology of a mixed inherited and infectious exposure (Greaves, 2018). Notably, BCP-ALL includes many genetic subtypes characterized by significant chromosomal alterations that result in the upregulation of genes by juxtaposition or dysregulation of proteins through the formation of chimeric genes (Malard and Mohty, 2020). These genes include hematopoietic transcription factors, epigenetic modifiers, cytokine receptors, and tyrosine kinases (Malard and Mohty, 2020). BCP-ALL cases usually carry a chromosome translocation as a primary genetic event, plus acquired secondary genetic alterations commonly affect cellular mechanisms that control B-cell differentiation and proliferation(Zhou et al., 2012).

The extensive genetic heterogeneity found within ALL in general, and BCP-ALL specifically represents a potential repository of biomarkers that could be harnessed for the

TABLE 1A | Cancer Type Detailed and numbers for lymphoid cancers and specifically the studies with lymphoblastic and Lymphoid leukemia [Acute Lymphoblastic Leukemia (St Jude, Nat Genet 2015), Acute Lymphoblastic Leukemia (St Jude, Nat Genet 2016), and Pediatric Acute Lymphoid Leukemia Phase II (TARGET, 2018)] used in our study.

\begin{tabular}{lcc}
\hline Cancer type detailed & Number & Percentage \\
\hline B-Lymphoblastic leukemia/lymphoma & 1978 & $92.26 \%$ \\
B-Cell acute lymphoid leukemia & 70 & $3.26 \%$ \\
T-Cell acute lymphoid leukemia & 8 & $0.37 \%$ \\
Acute lymphoblastic leukemia & 3 & $0.14 \%$ \\
Leukemia & 1 & $0.05 \%$ \\
Acute undifferentiated leukemia & 1 & $0.05 \%$ \\
Acute myeloid leukemia & 10 & $0.47 \%$ \\
Acute lymphoid leukemia & 73 & $3.40 \%$ \\
Total samples & 2144 & $100.00 \%$ \\
Total patients & 1706 &
\end{tabular}

TABLE 1B | Pediatric Acute Lymphoid Leukemia - Phase II (TARGET, 2018)] used in our study classified according to their cell of origin.

\begin{tabular}{lcc}
\hline Category & Number of samples & Percentage of samples \\
\hline B-precursor & 943 & $47.7 \%$ \\
B cell all & 726 & $36.7 \%$ \\
T cell all & 300 & $15.2 \%$ \\
NA & 9 & $0.5 \%$
\end{tabular}

\section{Step 1}

Explore cBioportal for Lymphoid Neoplasm
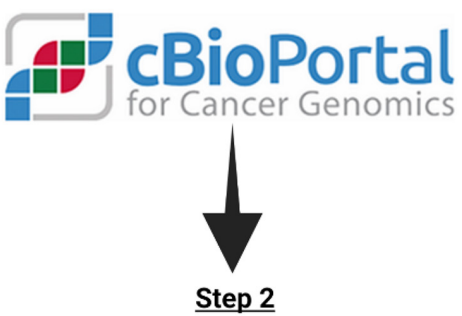

B-Lymphoblastic leukemia/lymphoma Studies were selected $(n=3)$

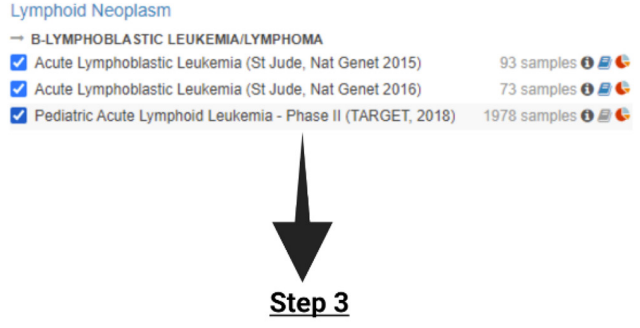

Only B-Lymphoblastic leukemia/lymphoma were selected

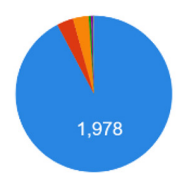

Cancer Type Detailed

E B-Lymphoblastic Leukemia/Lymphoma: 1978 (92.3\%)

- Acute Lymphoid Leukemia: 73 (3.4\%)

- B-Cell Acute Lymphoid Leukemia: 70 (3.3\%)

- Acute Myeloid Leukemia: $10(0.5 \%)$

- T-Cell Acute Lymphoid Leukemia: $8(0.4 \%)$

- Acute Lymphoblastic Leukemia: $3(0.1 \%)$

acute Undifferentiated Leukemia: $1(<0.1 \%)$

- Leukemia: $1(<0.1 \%)$

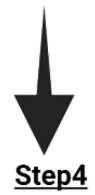

Only B-Precursor and B cell ALL were selected

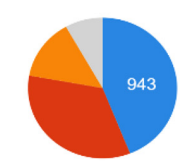

$$
\text { Cell of tumor origin }
$$

- B-Precursor: 943 (44.0\%) - B Cell ALL: $726(33.9 \%)$ E T Cell ALL: $300(14.0 \%)$

In $\mathrm{NA}: 175(8.2 \%)$

FIGURE 1 | The flowchart for the studies and samples selected for the analysis. 
TABLE 2 | Distribution of genes with the highest percentage of chromosomal changes in the profiled samples.

\begin{tabular}{|c|c|c|c|c|c|c|}
\hline Gene & Cytoband & CNA & Samples with the given CNA & Profiled samples & Percentage & Is cancer gene (source: OncoKB) \\
\hline ADAM6 & 14q32.33 & HOMDEL & 455 & 764 & $59.60 \%$ & No \\
\hline LINC00226 & 14q32.33 & HOMDEL & 355 & 764 & $46.50 \%$ & No \\
\hline FAM30A & $14 q 32.33$ & HOMDEL & 340 & 764 & $44.50 \%$ & No \\
\hline LINC00221 & 14q32.33 & HOMDEL & 307 & 764 & $40.20 \%$ & No \\
\hline CDKN2A & $9 p 21.3$ & HOMDEL & 276 & 764 & $36.10 \%$ & Yes \\
\hline CDKN2B & $9 p 21.3$ & HOMDEL & 257 & 764 & $33.60 \%$ & Yes \\
\hline CDKN2B-AS1 & $9 p 21.3$ & HOMDEL & 236 & 764 & $30.90 \%$ & No \\
\hline MTAP & $9 p 21.3$ & HOMDEL & 203 & 764 & $26.60 \%$ & Yes \\
\hline PRSS1 & $7 q 34$ & HOMDEL & 193 & 764 & $25.30 \%$ & Yes \\
\hline
\end{tabular}

CNA, copy number aberration.

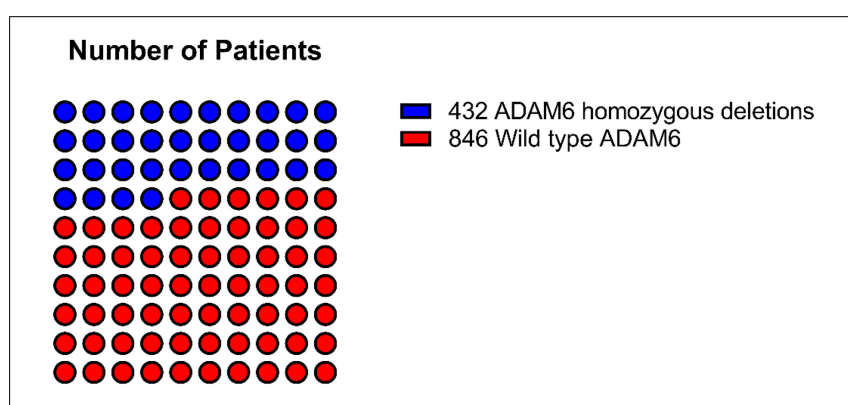

Total $=1278$

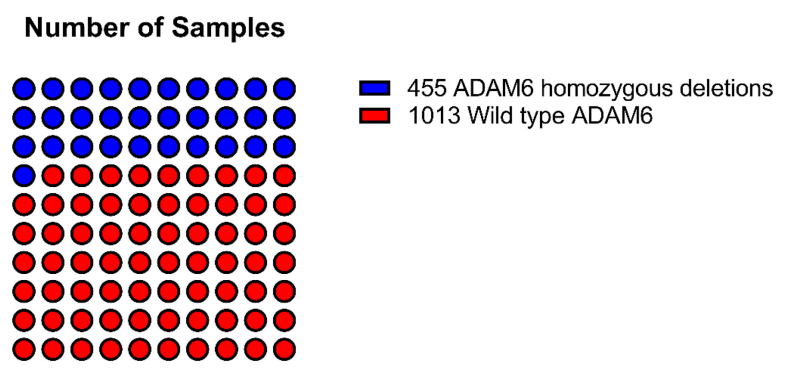

Total=1468

FIGURE 2 | Distribution of samples and patients with ADAM6 homozygous deletions compared to the rest with wild-type ADAM6.

development of early diagnostic and monitoring tools as well as novel chemotherapeutic targets. This is pertinent as cytogenetics plays a significant role in patients' diagnosis and risk stratification for treatment in childhood BCP-ALL (Schwab et al., 2013). The application of bioinformatics tools enables rapid screening for novel biomarkers, which can be further investigated for prognostic and predictive use to enhance personalized precision treatment. To facilitate this, we have carried out in silico analysis of publicly available ALL datasets to identify genetic biomarkers for childhood BCP-ALL, which could be used either individually or in combination as markers for early detection, risk stratification, and prognosis.

\section{MATERIALS AND METHODS}

\section{Explore Publicly Available Patients Clinical and Molecular Databases}

To explore the novel or less studied genes that show promising clinical and molecular signatures, we examined the cBioPortal online tool for publicly available datasets (Cerami et al., 2012). We searched for lymphoid cancers, and selected the three studies with lymphoblastic and lymphoid leukemia [Acute Lymphoblastic Leukemia (St Jude, Nat Genet 2015), Acute Lymphoblastic Leukemia (St Jude, Nat Genet 2016), and Pediatric Acute Lymphoid Leukemia - Phase II (TARGET, 2018)]. These are based in whole or part based upon data generated by the Therapeutically Applicable Research to Generate Effective Treatments ${ }^{1}$ initiative, phs000218. The data used for this analysis are available at https://portal.gdc.cancer.gov/projects.

In total, the three studies included 1706 total patients with 2144 samples. B-Lymphoblastic Leukemia/Lymphoma was the largest in the three studies with 1978 samples (Table 1A). To decrease heterogeneity of sample sources, only these 1978 B-Lymphoblastic Leukemia/Lymphoma samples were selected for further analysis. Pediatric Acute Lymphoid Leukemia - Phase II (TARGET, 2018) contains those 1978 samples, so we restricted

${ }^{1}$ https://ocg.cancer.gov/programs/target

TABLE 3 | Comparison of clinical attributes of ADAM6 homozygous deletion (ADAM6:HOMDEL) versus ADAM6 wild-type (WT:ADAM6) patients.

\begin{tabular}{|c|c|c|c|c|}
\hline Clinical attribute & Attribute type & Statistical test & $p$-Value & $q$-Value \\
\hline Diagnosis age & Patient & Wilcoxon test & $5.85 \mathrm{E}-07$ & $2.39 E-06$ \\
\hline $\begin{array}{l}\text { Diagnosis age } \\
\text { (days) }\end{array}$ & Patient & Wilcoxon test & 1.06E-06 & 3.99E-06 \\
\hline WBC & Patient & Wilcoxon test & $7.42 \mathrm{E}-05$ & 2.57E-04 \\
\hline $\begin{array}{l}\text { Alternative therapy } \\
\text { given }\end{array}$ & Patient & Chi-squared test & $9.64 \mathrm{E}-04$ & $3.10 E-03$ \\
\hline CNS status & Patient & Chi-squared test & $5.54 \mathrm{E}-08$ & 2.49E-07 \\
\hline First event & Patient & Chi-squared test & 0.0157 & 0.0353 \\
\hline $\begin{array}{l}\text { MRD Percentage } \\
\text { day } 8\end{array}$ & Patient & Wilcoxon test & 0.0231 & 0.0472 \\
\hline MRD Percentage & Patient & Wilcoxon test & $5.94 \mathrm{E}-10$ & $5.35 E-09$ \\
\hline
\end{tabular}



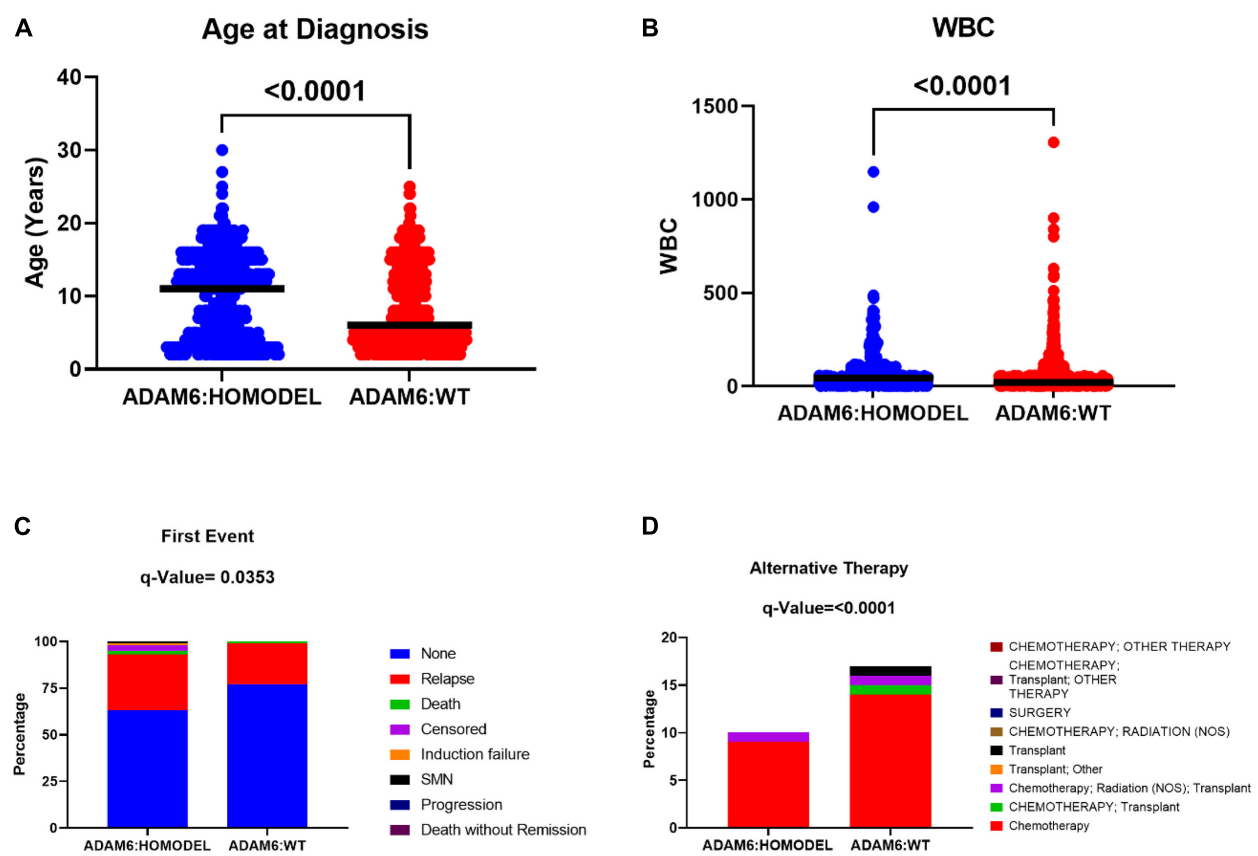

E

MRD Percentage Day 8

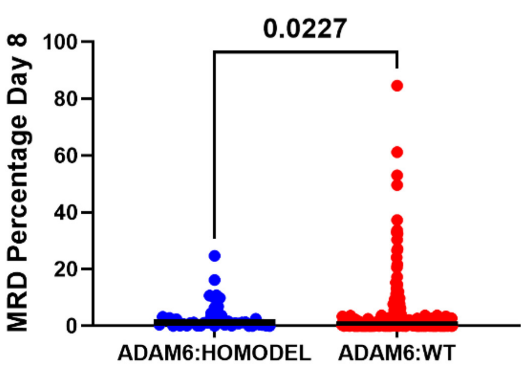

MRD Percentage Day 29 Sensitivity

$F$

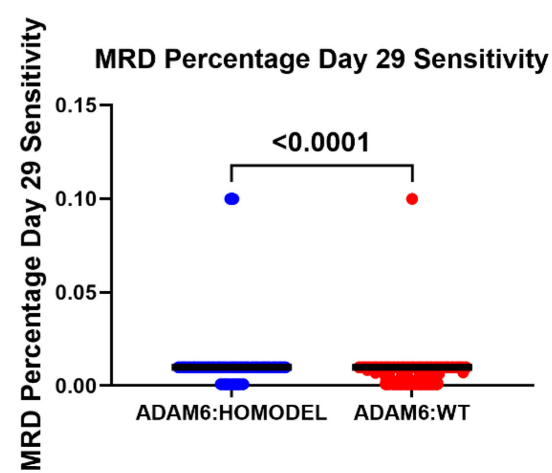

FIGURE 3 | The difference in the clinical attributes between ADAM6:HOMDEL versus WT:ADAM6 patients.
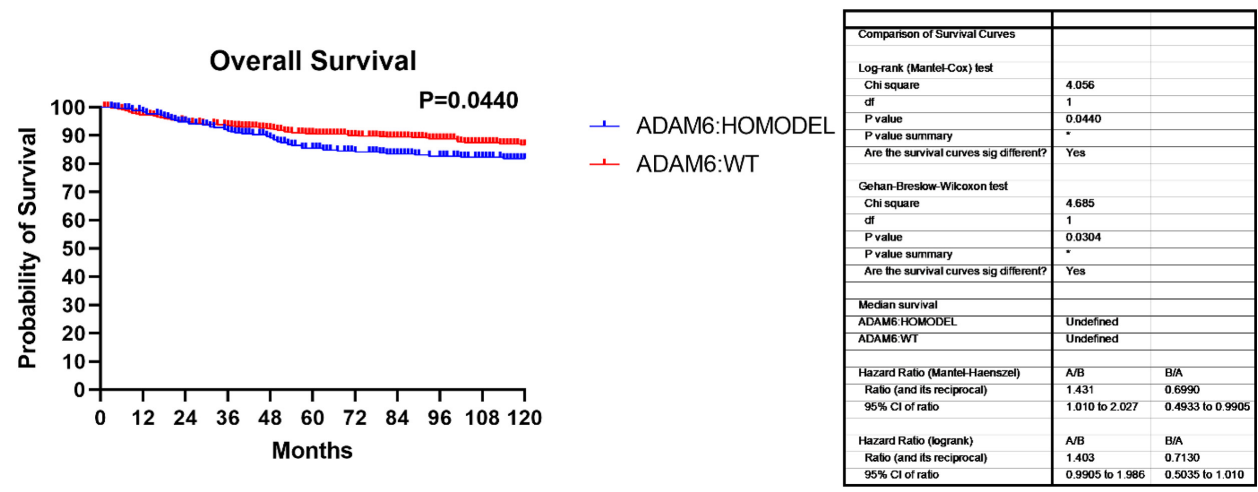

FIGURE 4 | Overall survival showing the ADAM6:HOMDEL versus WT:ADAM6. 
the further analysis according to the cell of origin in the study, so we excluded those from T cell ALL $(n=300)$ and kept only B-Precursor and B Cell ALL (Table 1B). The flowchart for the studies and samples selected for the analysis is shown in Figure 1.

\section{Molecular Differences Between the Identified Groups}

For downstream work, we used the cBioPortal tool to analyze the clinical and molecular profiles of patients. Chromosomal changes in the selected samples were assessed to determine if any novel genomic loci for the leukemia of lymphoid origin were identifiable. The subsequent analysis focused on distinguishing the profiles of patients who had the predominant novel genomic loci compared to those with intact or wild counterparts.

\section{miRNA Targets}

To determine the common targets of the identified miRNA, we used miRDB online database for miRNA target prediction and functional annotations ${ }^{2}$. The identified differentially expressed miRNA targets between the groups were intersected with the target of the rest of miRNA, and common targets among at least 4 out of the six miRNAs were selected. TargetScan ${ }^{3}$ was used to predict biological targets of miRNAs by searching for the presence of conserved $8 \mathrm{mer}, 7 \mathrm{mer}$, and $6 \mathrm{mer}$ sites that match the seed region of each miRNA(Agarwal et al., 2015).

\section{RESULTS}

\section{Identification of the Novel Genomic Loci Significant in Leukemia of Lymphoid Origin}

Interestingly we identified nine genes (ADAM6, LINC00226, FAM30A, LINC00221, CDKN2A, CDKN2B, CDKN2B-AS1, MTAP, and PRSS1) which had homozygous deletions present in more than $25 \%$ of profiled cases (Table 2 ). Additionally, most of these genes were found in two common loci where (ADAM6, LINC00226, FAM30A, and LINC00221 in 14q32.33 cytoband) and (CDKN2A, CDKN2B, CDKN2B-AS1, and MTAP in 9p21.3 cytoband). Of these nine genes, only four are known Cancer Genes in OncoKB (CDKN2A, CDKN2B, MTAP, and PRSS1), as shown in Table 2.

The frequency of ADAM6 homozygous deletion (ADAM6 HOM: DEL) was the highest among the nine genes (455 out of $764 ; 59.60 \%$ ); therefore, further analysis was carried out to examine the difference between patients with this deletion ( $n=455$ samples from 432 patients) and the patients without the deletion ( $n=846$ samples from 1013 patients) as shown in Figure 2 .

\footnotetext{
${ }^{2}$ http://mirdb.org/mirdb/

${ }^{3}$ http://www.targetscan.org/vert_72/
}

\section{Patients With ADAM6 HOM:DEL Showed a Distinct Clinical Profile}

To determine if there were clinical differences between patients with the ADAM6 HOM: DEL and those with intact ADAM6 (wild-type ADAM6 [WT:ADAM6]), the cBioPortal clinical comparison tools was used to compare the two groups. Compared to patients with WT:ADAM6, those with ADAM6 HOM:DEL presented at a later age, higher total WBC count, needed chemotherapy, radiation, and transplant as an alternative therapy, more relapse rate as the first event with higher minimal residual disease (MRD) at day 8 and 29 as shown in Table 3 and Figure 3.

Additionally, we found that patients with the ADAM6 HOM:DEL showed poor ten-year survival compared to those with intact ADAM6 (Figure 4).

\section{ADAM6 HOM:DEL Patients Showed Distinct Molecular Profile}

Samples from patients with ADAM6 HOM:DEL had B precursor predominantly as a cell of origin with specific molecular subtypes like higher frequencies of TCF3-PBX1, ETV6-RUNX1 Fusion, and less Trisomy 4_10 status. Furthermore, although ADAM6 HOM:DEL was associated with higher mutation counts and a less altered fraction of the genome, as shown in Table 4 and Figure 5.

\section{ADAM6 HOM:DEL Patients Showed Specific Deletion of Other Key Genes}

In patients with ADAM6 HOM:DEL, we identified other genes which were also deleted. The top genes with the highest deletion were (FAM30A, LINC00226, LINC00221, VPREB1, PRSS1, PRSS2, BCL2L14, LRP6, and ETV6). Of note, 3 of these genes (FAM30A, LINC00226, and LINC00221) are present in the same cytoband, while the other three genes (BCL2L14, LRP6, and ETV6) are located in the 12p13.2 cytoband. Two genes

TABLE 4 | Comparison of Molecular attributes of ADAM6 homozygous deletion (ADAM6:HOMDEL) versus ADAM6 wild-type (WT:ADAM6) patients.

\begin{tabular}{|c|c|c|c|c|}
\hline $\begin{array}{l}\text { Clinical } \\
\text { attribute }\end{array}$ & Attribute type & Statistical test & $p$-Value & $q$-Value \\
\hline $\begin{array}{l}\text { Cell of tumor } \\
\text { origin }\end{array}$ & Sample & Chi-squared test & 0 & 0 \\
\hline $\begin{array}{l}\text { TCF3-PBX1 } \\
\text { status }\end{array}$ & Sample & Chi-squared test & 8.62E-03 & 0.0215 \\
\hline $\begin{array}{l}\text { Mutation } \\
\text { count }\end{array}$ & Sample & Wilcoxon test & 0.0151 & 0.0353 \\
\hline $\begin{array}{l}\text { Fraction } \\
\text { genome } \\
\text { altered }\end{array}$ & Sample & Wilcoxon test & 0.0221 & 0.0472 \\
\hline $\begin{array}{l}\text { ETV6-RUNX1 } \\
\text { fusion status }\end{array}$ & Sample & Chi-squared test & $1.67 \mathrm{E}-15$ & $1.87 \mathrm{E}-14$ \\
\hline $\begin{array}{l}\text { Molecular } \\
\text { subtype }\end{array}$ & Sample & Chi-squared test & $3.92 \mathrm{E}-08$ & $1.96 \mathrm{E}-07$ \\
\hline Trisomy 4_10 & Sample & Chi-squared test & $6.52 \mathrm{E}-09$ & $4.19 E-08$ \\
\hline DNA index & Sample & Chi-squared test & $2.05 \mathrm{E}-03$ & $6.16 \mathrm{E}-03$ \\
\hline MLL status & Sample & Chi-squared test & $1.33 E-08$ & $7.49 \mathrm{E}-08$ \\
\hline
\end{tabular}




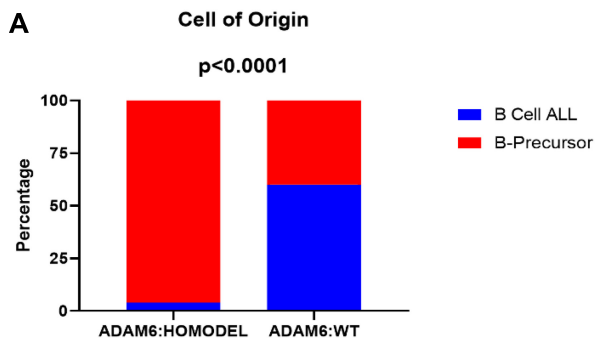

C

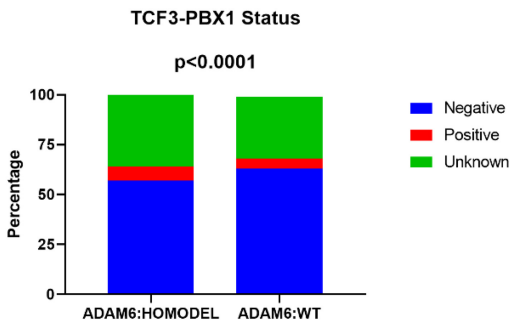

E

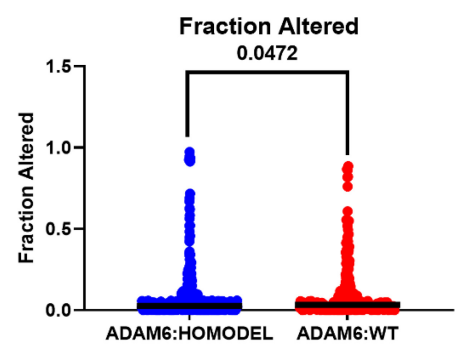

B

CNS Site of Relapse

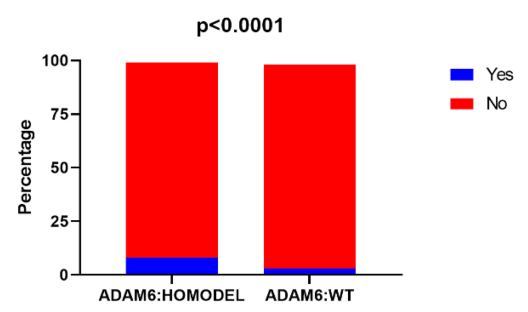

D

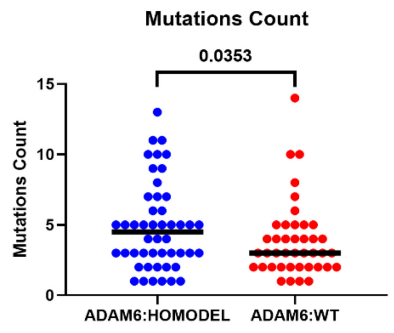

$\mathbf{F}$

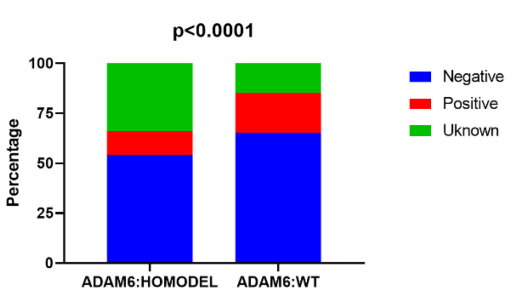

G

H

Tisomy 410

$p<0.0001$
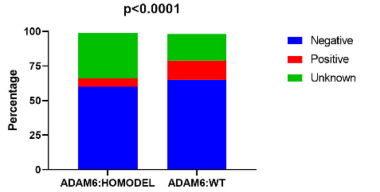

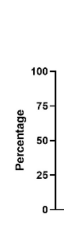

MLL Status

$\mathrm{p}<0.0001$

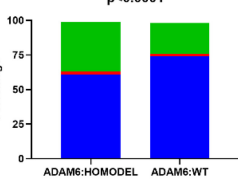

ENegative
E Postive
Unnown

DNA Index

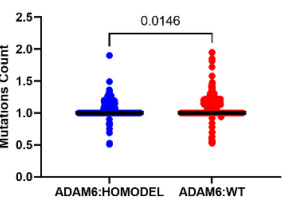

$\mathbf{J}$

Molecular Subtypes

$p<0.0001$

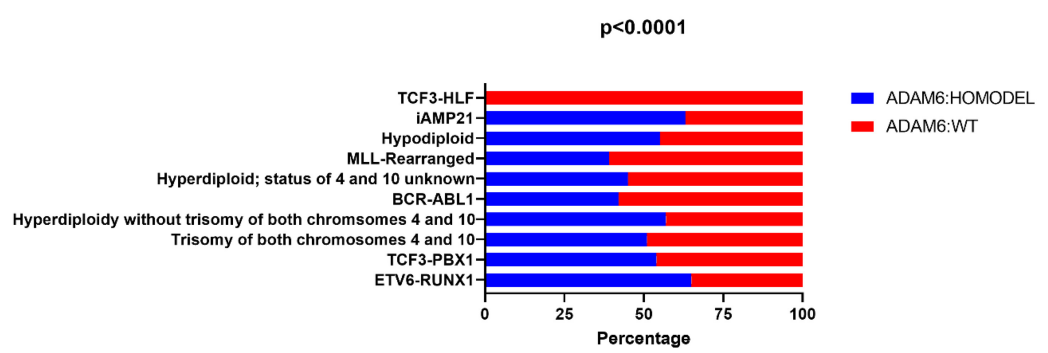

FIGURE 5 | Comparison of Molecular attributes of ADAM6 homozygous deletion (ADAM6:HOMDEL) versus ADAM6 wild-type (WT:ADAM6) patients. 
TABLE 5 | Most frequently deleted genes in ADAM6 homozygous deletion (ADAM6:HOMDEL) versus ADAM6 wild-type (WT:ADAM6) patients.

\begin{tabular}{|c|c|c|c|c|c|c|}
\hline Gene & Cytoband & (A) ADAM6:HOMDEL & (B) WT:ADAM6 & Log Ratio & $p$-Value & $q$-Value \\
\hline ADAM6 & $14 q 32.33$ & 432 (100.00\%) & $0(0.00 \%)$ & $>10$ & $7.45 E-194$ & $1.24 \mathrm{E}-189$ \\
\hline FAM30A & 14q32.33 & 309 (71.53\%) & 19 (7.60\%) & 3.23 & 2.06E-65 & $1.72 \mathrm{E}-61$ \\
\hline LINC00226 & 14q32.33 & 301 (69.68\%) & $36(14.40 \%)$ & 2.27 & 4.06E-47 & 2. $26 \mathrm{E}-43$ \\
\hline LINC00221 & $14 q 32.33$ & 249 (57.64\%) & 48 (19.20\%) & 1.59 & $1.29 E-23$ & 5.36E-20 \\
\hline VPREB1 & $22 q 11.22$ & $128(29.63 \%)$ & 20 (8.00\%) & 1.89 & $2.90 \mathrm{E}-12$ & $9.68 \mathrm{E}-09$ \\
\hline PRSS1 & $7 q 34$ & $151(34.95 \%)$ & $36(14.40 \%)$ & 1.28 & 1.87E-09 & $5.21 \mathrm{E}-06$ \\
\hline PRSS2 & $7 q 34$ & $104(24.07 \%)$ & $19(7.60 \%)$ & 1.66 & $1.32 \mathrm{E}-08$ & $3.14 \mathrm{E}-05$ \\
\hline BCL2L14 & $12 \mathrm{p} 13.2$ & $57(13.19 \%)$ & $5(2.00 \%)$ & 2.72 & 8.57E-08 & $1.59 \mathrm{E}-04$ \\
\hline LRP6 & $12 \mathrm{p} 13.2$ & 57 (13.19\%) & $5(2.00 \%)$ & 2.72 & 8.57E-08 & $1.59 \mathrm{E}-04$ \\
\hline ETV6 & 12p13.2 & 70 (16.20\%) & $9(3.60 \%)$ & 2.17 & 1.02E-07 & $1.70 \mathrm{E}-04$ \\
\hline
\end{tabular}

${ }^{*} q$-Value < 0.05 significant, ADAM6:HOMDEL, ADAM6 homozygous deletion; WT:ADAM6, ADAM6 wild-type.

TABLE 6 | Specific microRNA changes between the ADAM6 HOM:DEL group and the rest of the patients.

\begin{tabular}{|c|c|c|c|c|c|c|c|c|}
\hline Gene & $\begin{array}{c}\text { Mean Log2 } \\
\text { expression } \\
\text { ADAM6:HOMDEL }\end{array}$ & $\begin{array}{c}\text { The standard } \\
\text { deviation of lo2 } \\
\text { expression } \\
\text { ADAM6:HOMDEL }\end{array}$ & $\begin{array}{l}\text { Mean Log2 } \\
\text { expression } \\
\text { WT:ADAM6 }\end{array}$ & $\begin{array}{l}\text { The standard } \\
\text { deviation of lo2 } \\
\text { expression } \\
\text { WT:ADAM6 }\end{array}$ & Log Ratio & $p$-Value & $q$-Value & $\begin{array}{c}\text { Higher } \\
\text { expression in }\end{array}$ \\
\hline MIR-6735/3P & 1.7 & 2.35 & 0.61 & 0.74 & 1.09 & $1.09 \mathrm{E}-04$ & 0.0452 & ADAM6:HOMDEL \\
\hline MIR-6735/5P & 1.7 & 2.35 & 0.61 & 0.74 & 1.09 & 1.09E-04 & 0.0452 & ADAM6:HOMDEL \\
\hline MIR-6734/3P & 2.32 & 2.76 & 0.92 & 1.34 & 1.4 & $9.21 \mathrm{E}-05$ & 0.0452 & ADAM6:HOMDEL \\
\hline MIR-574/574 & 78.95 & 89.45 & 33.81 & 44.55 & $>10$ & $1.04 \mathrm{E}-04$ & 0.0452 & ADAM6:HOMDEL \\
\hline MIR-574/5P & 78.95 & 89.45 & 33.81 & 44.55 & $>10$ & $1.04 \mathrm{E}-04$ & 0.0452 & ADAM6:HOMDEL \\
\hline
\end{tabular}

${ }^{*} q$-Value < 0.05 significant, ADAM6:HOMDEL, ADAM6 homozygous deletion; WT:ADAM6, ADAM6 wild-type.

(PRSS1and PRSS2) are present on 12p13.2, while VPREB1 was the only gene on 22q11.22 as listed in the Table 5.

\section{ADAM6 HOM:DEL Is Associated With Unique mRNA and microRNA Genes Expression}

To examine if there are specific mRNA changes between patients with ADAM6 HOM:DEL and those without ADAM6 deletion, the mRNA expression (microarray) comparison tool of cBioPortal was used. Our findings showed specific significant differential expression of 1080 genes between the two groups. To examine if there are specific microRNA changes between patients with ADAM6 HOM:DEL and those without ADAM6 deletion, the miRNA comparison tool of cBioPortal was used. Our findings showed specific significant differential expression of 3 pairs of miRNA targets (MIR-574/3P MIR-574/574, MIR574/5P, MIR-6734/3P, MIR-6734/5P, MIR-6735/3P, and MIR6735/5P) as shown in Table 6 and Figure 6.

MicroRNAs (miRNAs) are small non-coding RNAs that act as master regulators of the expression of their gene targets, so predicting miRNA targets is a vital step in the characterization of miRNA functions (Chen and Wang, 2019). We surmised that if the miRNA target the same genes, we might identify a novel mechanism that controls the Differentially expressed genes (DEGs) between the two groups. Therefore, to determine the common targets of the identified miRNA, we used miRDB online database for miRNA target prediction and functional annotations $^{2}$ for analysis. The target of each miRNA was intersected with the target of the rest miRNA and common targets among at least 4 out of the six miRNAs were selected (Table 7).

Our findings show that myocyte-enhancer factor $2 \mathrm{C}$ (MEF2C) was common between 5 miRNA targets. In order to identify the putative binding sequence of the target gene (MEF2C) and binding scores, we used targetscan online tool ${ }^{3}$ to search for MEF2C-miRNA interactions. The identifier MEF2C corresponds to 2 transcripts. One is the representative (most prevalent) transcript for MEF2C (ENST00000340208.5) and The second is the less prevalent transcript for MEF2C (ENST00000506554.1). The MEF2C-miRNA interactions, binding sites, and scores are shown in Table 8.

In order to understand the correlation between MEF2C and different leukemias, we explored BloodSpot ${ }^{4}$ "a database of gene expression profiles and transcriptional programs for healthy and malignant hematopoiesis"(Bagger et al., 2015) looking for MEF2C expression. MEF2C expression showed its specificity to ALL, as shown in Figure 7.

\section{PRSS1, ACOT11, NTRK2, NOVA2, and SEMA7A Might Be the Novel Players in ADAM6 HOM:DEL ALL}

Finally, to determine if common players link genomics, transcriptomics, and miRNA together, we intersected the

\footnotetext{
${ }^{4}$ http://servers.binf.ku.dk/bloodspot/
} 


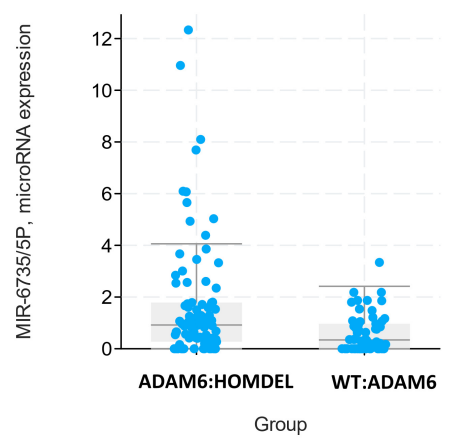

p-Value: $1.085 \mathrm{e}-4$

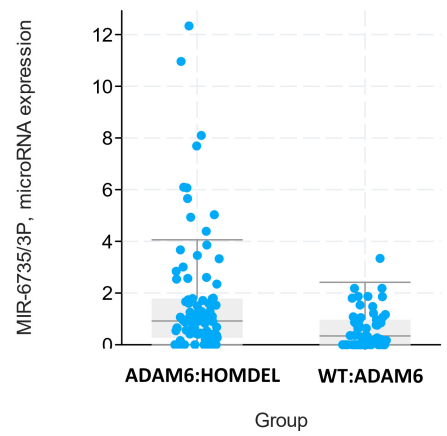

p-Value: $1.085 \mathrm{e}-4$

q-Value: 0.0452

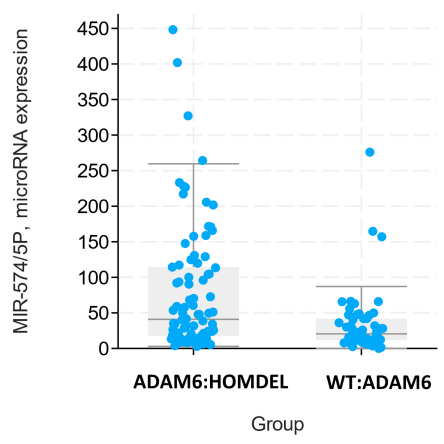

p-Value: $1.044 \mathrm{e}-4$

q-Value: 0.0452

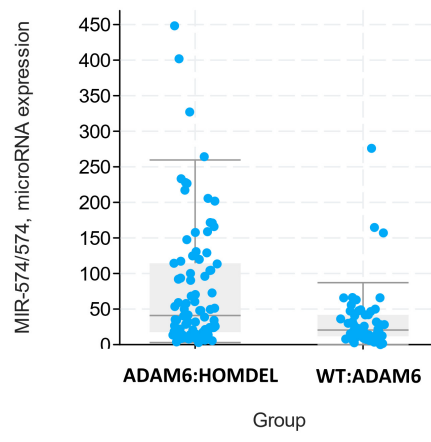

p-Value: $1.044 \mathrm{e}-4$

q-Value: 0.0452

p-Value: $9.207 e-5$

q-Value: 0.0452

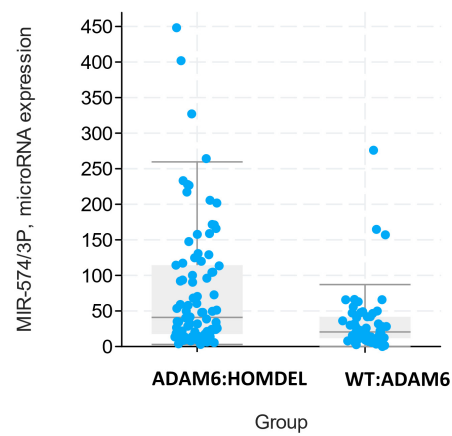

p-Value: $1.044 \mathrm{e}-4$

q-Value: 0.0452

p-Value: $9.207 e-5$

q-Value: 0.0452

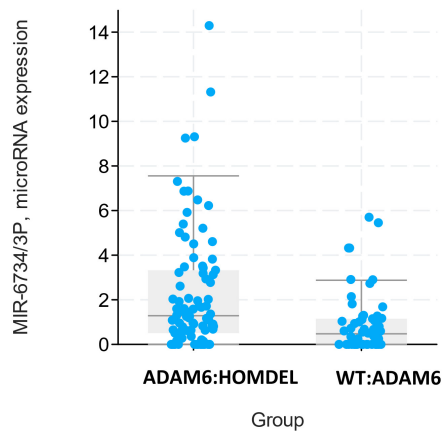

FIGURE 6 | The top statistically different miRNA between ADAM6:HOMDEL versus WT:ADAM6 patients.

commonly deleted genes, the DEGs, and the shared miRNA targets. Our findings identified the common genes as PRSS1, ACOT11, NTRK2, NOVA2, and SEMA7A, suggesting that they might be the novel players in ADAM6 HOM:DEL ALL as shown in Figure 8.

\section{DISCUSSION}

Our findings demonstrate that patients with ADAM6 HOM:DEL had a distinct clinical profile compared to those with intact ADAM6. These findings suggest a possible role for ADAM6 
TABLE 7 | Shared targets by the specific microRNA changed between the ADAM6 HOM:DEL group and the rest of the patients.

[hsa-miR-6735-3p] and [hsa-miR-6735-5] and [hsa-miR-6734-3] and [hsa-miR-6734-5p]

[hsa-miR-6735-3p] and [hsa-miR-6735-5] and [hsa-miR-574-5p] and [hsa-miR-6734-3] [hsa-miR-6735-3p] and [hsa-miR-6735-5] and [hsa-miR-574-5p] and [hsa-miR-6734-5p] [hsa-miR-6735-3p] and [hsa-miR-6735-5] and [hsa-miR-574-5p] and [hsa-miR-6734-3] and [hsa-miR-6734-5p]
CCDC85C, ACVR2B, NOVA2, TBC1D16, FKTN, STIM1, HLA-DQA1, C6orf106 KIAA0513, TMEM106A, DCAF8, SEMA7A NOS1, NTRK2, FOXN3, MASP1 MEF2C

TABLE 8 | The MEF2C-miRNA interactions, binding sites and scores as per Targetscan tools.

\begin{tabular}{|c|c|c|c|c|c|c|}
\hline $\begin{array}{l}\text { TargetScan_7.2 } \\
\text { ENST00000340208.5 }\end{array}$ & $\begin{array}{c}\text { Position in the } \\
\text { UTR }\end{array}$ & seed match & context ++ score & $\begin{array}{c}\text { context }++ \text { score } \\
\text { percentile }\end{array}$ & $\begin{array}{c}\text { weighted } \\
\text { context }++ \text { score }\end{array}$ & $\begin{array}{c}\text { conserved } \\
\text { branch length }\end{array}$ \\
\hline hsa-miR-6734-3p & $65-71$ & 7 mer-m8 & -0.12 & 79 & -0.12 & 0 \\
\hline hsa-miR-574-5p & $2370-2377$ & 8mer & -0.27 & 90 & -0.02 & 0 \\
\hline hsa-miR-6734-3p & 2814-2820 & 7 mer-m8 & -0.2 & 89 & -0.02 & 0 \\
\hline hsa-miR-6735-5p & $3427-3433$ & 7 mer-m8 & -0.1 & 69 & -0.01 & 0.322 \\
\hline hsa-miR-6734-5p & $3595-3601$ & 7 mer-1A & -0.11 & 67 & -0.01 & 0.159 \\
\hline $\begin{array}{l}\text { TargetScan_7.2 } \\
\text { ENST00000506554.1 }\end{array}$ & $\begin{array}{l}\text { Position in the } \\
\text { UTR }\end{array}$ & seed match & context + + score & $\begin{array}{c}\text { context }++ \text { score } \\
\text { percentile }\end{array}$ & $\begin{array}{c}\text { weighted } \\
\text { context }++ \text { score }\end{array}$ & $\begin{array}{c}\text { conserved } \\
\text { branch length }\end{array}$ \\
\hline hsa-miR-6734-3p & $214-220$ & 7 mer-m8 & -0.11 & 76 & -0.11 & 0 \\
\hline hsa-miR-574-5p & 2519-2526 & 8mer & -0.28 & 91 & 0 & 0 \\
\hline hsa-miR-6735-5p & 3576-3582 & 7 mer-m8 & -0.11 & 71 & 0 & 0.322 \\
\hline hsa-miR-6734-5p & $3744-3750$ & 7 mer-1A & -0.11 & 68 & 0 & 0.159 \\
\hline
\end{tabular}

in disease pathogenesis, progression, and patient survival. The finding of significant differences in the 10-year survival rate between patients with ADAM6 HOM:DEL versus those with intact ADAM6 is of interest as this could potentially be used as a novel biomarker for monitoring the development and progression of BCP-ALL. ADAM6 is a member of a disintegrin and metalloproteinases (ADAMs) gene family of proteins which display a common domain organization featuring a pro-domain, a metalloprotease, a disintegrin, a cysteine-rich, an epidermal growth factor-like, and a transmembrane domain, as well as a C-terminal cytoplasmic tail (Wolfsberg et al., 1995; Brocker et al., 2009). ADAM members are multifunctional proteins involved in the proteolytic processing of other transmembrane proteins, cell adhesion, and cell signaling events (Weber and Saftig, 2012). Several reports have shown that members of the ADAM family are overexpressed in human cancers such as ADAM8 in human renal cell carcinomas, ADAM15 in lung carcinoma, and ADAM17 in breast cancers (Mochizuki and Okada, 2007). Differences in the active site sequence of the metalloproteinase domain indicate that $60 \%$ of ADAM members are pseudogenes and non-proteolytic molecules; as a result, several members of the ADAM family, including ADAM6, a pseudogene located in chromosome 14 (14q32.33), have hitherto not been well studied or reported on in the literature (Mochizuki and Okada, 2007). Indeed, the function of ADAM6 in disease or normal physiological scenarios is yet to be fully elucidated and our findings are an essential contribution to the paucity of data on ADAM6.

Interestingly, our study noted specific microRNA changes in patients with ADAM6 HOM:DEL where the expression of MIR-574/3P gene was observed in most ADAM6 HOM:DEL suggesting an association between ADAM6 deletion and the overexpression of the gene. Since $M I R-574 / 3 P$ gene is known to suppress proliferation and induces apoptosis of chronic myeloid leukemia (CML) cells via targeting IL6/JAK/STAT3 pathway (Yang et al., 2018), the findings of this study provide novel insights into the association of ADAM6 with miR-574$3 p$ signaling pathway in leukemia. Furthermore, the findings demonstrate that the deletion of ADAM6 is associated with unique microRNA genes expression with significant differential expression of 3 pairs of miRNA targets. The MEF2C gene was the one most linked showing an association with 5 of these miRNA targets. $M E F 2 C$ is necessary for the proper development of megakaryocytes and platelets and bone marrow B-lymphopoiesis. Moreover, $M E F 2 C$ is required for $\mathrm{B}$-cell survival and proliferation in response to $\mathrm{B}$ cell receptor (BCR) stimulation, efficient IgG1 antibody responses to $\mathrm{T}$-cell-dependent antigens, and normal germinal center induction B-cells. This gene is a selectively expressed transcription factor that, if ectopically expressed due to chromosomal rearrangements, can lead to mixed-lineage leukemia-rearranged acute myeloid leukemia and immature T-cell acute lymphoblastic leukemia (Canté-Barrett et al., 2014). Phosphorylation of $M E F 2 C$ has been reported in the majority of primary chemotherapy-resistant AML (Brown et al., 2018). Its high expression is linked with a subset of AML patients with adverse-risk disease features and poor outcomes, with confirmation that high MEF2C mRNA expression leads to overexpression of MEF2C protein (Laszlo et al., 2015). These findings provided the rationale for the therapeutic targeting of MEF2C transcriptional activation in AML. The finding of $M E F 2 C$ as a common link among the miRNA targets in ADAM6 $H O M: D E L$ patients suggests the potential role for this gene in disease progression, which warrants further investigation of its use as a biomarker. 


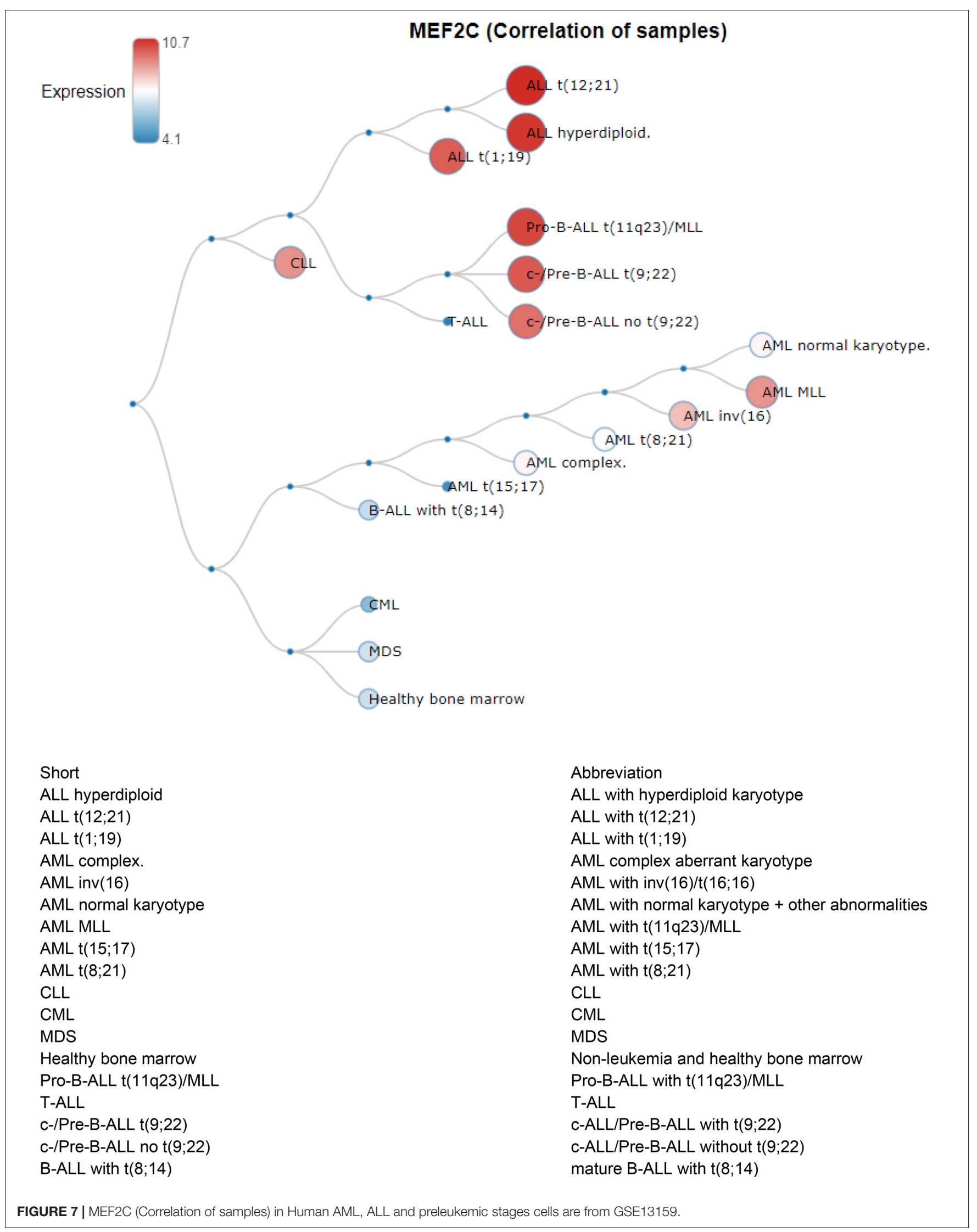




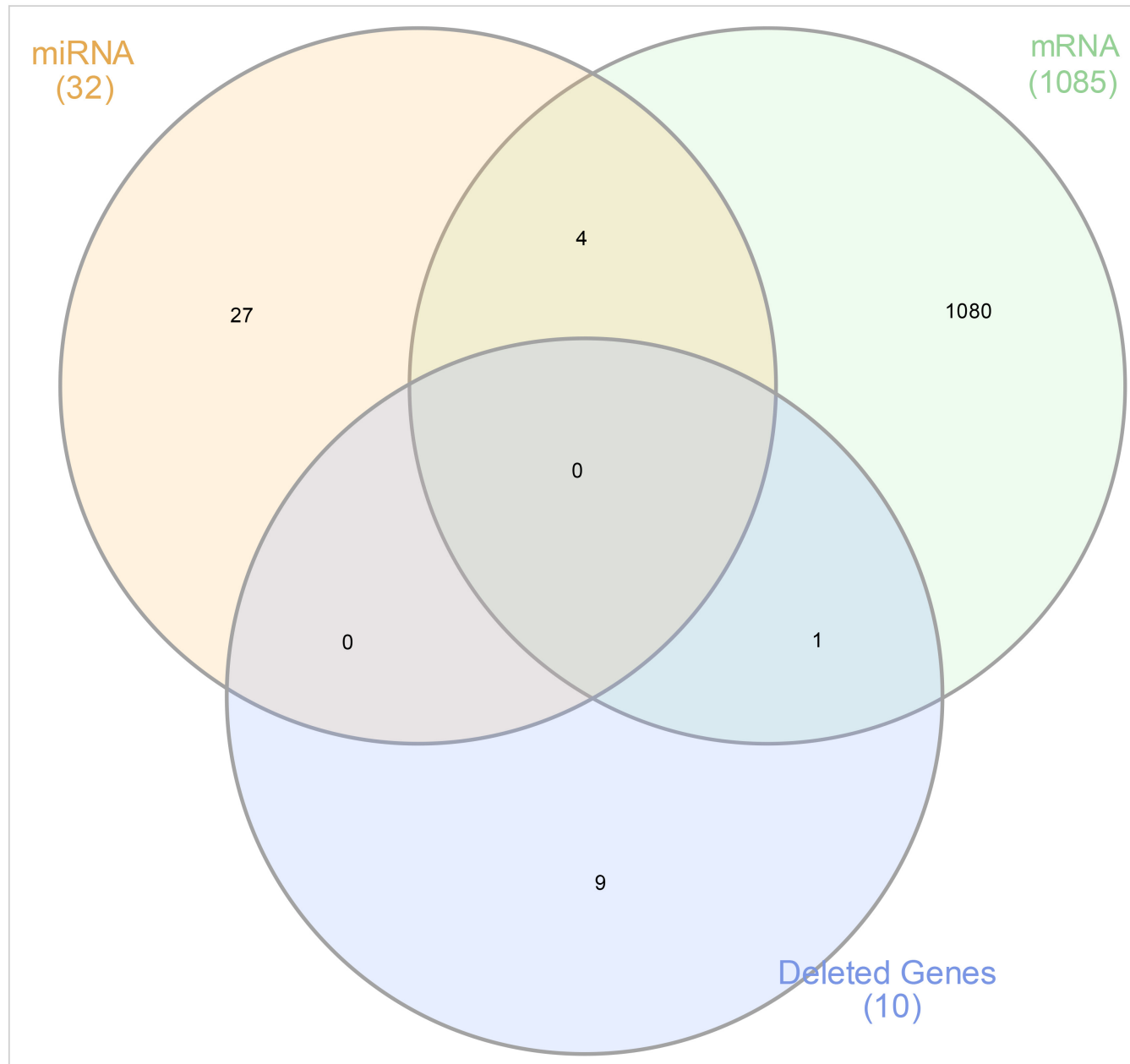

\begin{tabular}{l|l|} 
Gene Symbol & Description \\
\hline PRSS1 & serine protease 1 \\
\hline ACOT11 & acyl-CoA thioesterase 11 \\
\hline NTRK2 & $\begin{array}{l}\text { neurotrophic receptor } \\
\text { tyrosine kinase 2 }\end{array}$ \\
\hline NOVA2 & $\begin{array}{l}\text { NOVA alternative } \\
\text { splicing regulator 2 }\end{array}$ \\
\hline SEMA7A & $\begin{array}{l}\text { semaphorin 7A (John } \\
\text { Milton Hagen blood } \\
\text { group) }\end{array}$ \\
\hline
\end{tabular}

Biological Process (GO)

GO:0009235 cobalamin metabolic process;GO:0033013 tetrapyrrole metabolic process;GO:0022617 extracellular matrix disassembly

GO:0009409 response to cold;GO:0120163 negative regulation of cold-induced thermogenesis;GO:0006637 acyl-CoA metabolic process

GO:0099183 trans-synaptic signaling by BDNF, modulating synaptic transmission;GO:0099191 transsynaptic signaling by BDNF;GO:0099540 trans-synaptic signaling by neuropeptide

GO:0120163 negative regulation of cold-induced thermogenesis;GO:0000381 regulation of alternative mRNA splicing, via spliceosome;GO:0000380 alternative mRNA splicing, via spliceosome

GO:0060907 positive regulation of macrophage cytokine production;GO:0010935 regulation of macrophage cytokine production;GO:0010934 macrophage cytokine production 
Our findings also demonstrate that the PRSS1, ACOT11, NTRK2, NOVA2, and SEMA7A genes were common denominators linking the unique genomic, transcriptomic, and miRNA profiles identified in the ADAM6 HOM:DEL ALL patients. This is pertinent as PRSS1, ACOT11, NTRK2 have been shown individually to play a role in other hematopoietic and solid organ malignancies but have hitherto not been previously reported in the context of BCPALL. Trypsin-encoding PRSS1-PRSS2 variations influence the risk of asparaginase-associated pancreatitis in children with acute lymphoblastic leukemia (Wolthers et al., 2019). Recent genome-wide association studies have found different candidate single-nucleotide polymorphisms associated with pancreatitis in patients with ALL (Rank et al., 2019). AcylCoA Thioesterase 11 (ACOT11) is a protein-coding gene, and its high expression in patients with lung adenocarcinoma was associated with cell proliferation and poor prognosis (Hung et al., 2017). In AML, high ACOT11 expression was associated with poor overall survival (Luo et al., 2016). In clear (ccRCC), ACOT11 has been identified as a diagnostic marker wherein mRNA level of ACOT11 was decreased compared to those in normal kidneys (Luo et al., 2016). Neurotrophic receptor tyrosine kinase 2 (NTRK2) is a kinase target for differentially expressed glutathione peroxidases (GPX-8) in AML (Wei et al., 2020). NTRK2 has been implicated in several types of cancers, including neuroblastoma, medulloblastoma, Wilm's tumor, and adenocarcinomas of the lung, prostate, and pancreas as well as multiple myeloma (Yuzugullu et al., 2016). In hematopoietic cells, B and T lymphocytes and monocytes have been shown to produce NTRK2 ligand (Kerschensteiner et al., 1999). NTRK2 and its ligand, brain-derived neurotrophic factors (BDNF), are coexpressed in acute leukemia blasts and negatively correlate with leukemia patients' survival. Studies have shown that mice with bone marrow transduced with both NTRK2 and BDNF developed AML and T-ALL (Uren and Turnley, 2014). NTRK2 overexpression is enriched in a subset of PTENdeficient T-ALL (Yuzugullu et al., 2016). Additionally, NTRK2 activation cooperates with PTEN deficiency to promote the proliferation of $\mathrm{Ba} / \mathrm{F} 3$ cells in the absence of IL3 in T-ALL (Yuzugullu et al., 2016).

Our assessment of the clinical profiles showed that patients with ADAM6 HOM:DEL were more likely to have the CNS as the site of relapse. This is interesting as two genes, namely NOVA2 and SEMA7A, were among common players linking the unique genomic, transcriptomic, and miRNA profiles in ADAM6 HOM:DEL ALL patients play important roles in CNS development and regulation. Neuro-Oncological Ventral Antigen 2 (NOVA2) is one of two NOVA proteins involved in neuronal-specific alternative splicing and is mainly expressed in the cerebral cortex and hippocampus (Yang et al., 1998). NOVA2 seems to be mainly associated with a splicing regulation of genes involved in axonal guidance and projection during the development of the cortex and genes implicated in the cerebellar function of synapse formation (Saito et al., 2016). It regulates a series of alternative splicing events linked to neurite outgrowth and axonal projections in human neural stem cells (Mattioli et al., 2020). Semaphorin 7A (SEMA7A) is a membrane-anchored protein that plays a critical role in neuronal pathfinding and axon guidance in selected areas of the developing nervous system. It is also known to be expressed widely with diverse functions, including immune cell modulation, bone remodeling, and drug resistance (Yazdani and Terman, 2006). SEMA7A is the only GPI-linked protein in the semaphorin family that is prominently expressed in the embryo, in the lymphoid organs, and in the nervous system of adult mice (Sato and Takahashi, 1998), it enhances central and peripheral axon growth and is required for proper axon tract formation during embryonic development (Pasterkamp et al., 2003). Though the precise function of Sema7A in the immune system remains unclear, Sema7A has been shown to stimulate human monocytes (Holmes et al., 2002), and its function as a negative regulator of $\mathrm{T}$-cell responses has also been reported (Czopik et al., 2006).

Overall, our findings provide the first insight to indicate that these genes might work together in the context of ADAM6 deletion. We hypothesize that they might play critical roles in determining the disease pathogenesis and progression in patients with deletion of ADAM6. This is in keeping with the poor patient survival trends demonstrated for ADAM6 HOM:DEL. Therefore, the identification ADAM6 deletion in BCP-ALL can be used as a genetic biomarker disease progression and prognosis.

\section{CONCLUSION}

The findings suggest that ADAM6 can be a novel genetic biomarker for risk stratification and prognosis of childhood BCP-ALL. The ADAM6 HOM:DEL is significantly associated with unique microRNA gene expression and is significantly associated with the deletion of essential genes. More research on the underlying signal to explore the molecular pathways and interacting genes is warranted. Comparing ALL patients with and without ADAM6 HOM:DEL in the prospective study can evaluate the predictive value of this promising marker, and making stable lymphoid cancer cells carrying such deletion to compare its biological and signaling derangement might explore such novel molecular changes related to ALL.

\section{DATA AVAILABILITY STATEMENT}

The datasets presented in this study can be found in online repositories. The names of the repository/repositories and accession number(s) can be found in the article/ supplementary material.

\section{AUTHOR CONTRIBUTIONS}

All authors listed have made a substantial, direct and intellectual contribution to the work, and approved it for publication. 


\section{REFERENCES}

Agarwal, V., Bell, G. W., Nam, J. W., and Bartel, D. P. (2015). Predicting effective microRNA target sites in mammalian mRNAs. eLife 4:e05005.

Bagger, F. O., Sasivarevic, D., Sohi, S. H., Laursen, L. G., Pundhir, S., Sønderby, C. K., et al. (2015). BloodSpot: a database of gene expression profiles and transcriptional programs for healthy and malignant haematopoiesis. Nucleic Acids Res. 44, D917-D924.

Brocker, C. N., Vasiliou, V., and Nebert, D. W. (2009). Evolutionary divergence and functions of the ADAM and ADAMTSgene families. Hum. Genomics 4, 43-55. doi: 10.1186/1479-7364-4-1-43

Brown, F. C., Still, E., Koche, R. P., Yim, C. Y., Takao, S., Cifani, P., et al. (2018). MEF2C phosphorylation is required for chemotherapy resistance in acute myeloid leukemia. Cancer Discov. 8, 478-497.

Canté-Barrett, K., Pieters, R., and Meijerink, J. P. (2014). Myocyte enhancer factor 2C in hematopoiesis and leukemia. Oncogene 33, 403-410. doi: 10.1038/onc. 2013.56

Cerami, E., Gao, J., Dogrusoz, U., Gross, B. E., Sumer, S. O., Aksoy, B. A., et al. (2012). The cBio cancer genomics portal: an open platform for exploring multidimensional cancer genomics data. Cancer Discov. 2, 401-404. doi: 10. 1158/2159-8290.cd-12-0095

Chen, Y., and Wang, X. (2019). miRDB: an online database for prediction of functional microRNA targets. Nucleic Acids Res. 48, D127-D131.

Czopik, A. K., Bynoe, M. S., Palm, N., Raine, C. S., and Medzhitov, R. (2006). Semaphorin $7 \mathrm{~A}$ is a negative regulator of $\mathrm{T}$ Cell responses. Immunity 24, 591-600. doi: 10.1016/j.immuni.2006.03.013

Giddings, B. M., Whitehead, T. P., Metayer, C., and Miller, M. D. (2016). Childhood leukemia incidence in California: high and rising in the hispanic population. Cancer 122, 2867-2875. doi: 10.1002/cncr.30129

Greaves, M. (2018). A causal mechanism for childhood acute lymphoblastic leukaemia. Nat. Rev. Cancer 18, 471-484. doi: 10.1038/s41568-0180015-6

Holmes, S., Downs, A. M., Fosberry, A., Hayes, P. D., Michalovich, D., Murdoch, P., et al. (2002). Sema7A is a potent monocyte stimulator. Scand. J. Immunol. 56, 270-275. doi: 10.1046/j.1365-3083.2002.01129.x

Howlader, N., Noone, Am, Krapcho, M., Miller, D., Brest, A., Yu, M., et al. (eds) (2021). SEER Cancer Statistics Review, 1975-2018. Bethesda, MD: National Cancer Institute.

Hung, J. Y., Chiang, S. R., Liu, K. T., Tsai, M. J., Huang, M. S., Shieh, J. M., et al. (2017). Overexpression and proliferation dependence of acyl-CoA thioesterase 11 and 13 in lung adenocarcinoma. Oncol. Lett, 14, 3647-3656. doi: 10.3892/ol. 2017.6594

Ibrahimova, A., Pommert, L., and Breese, E. H. (2021). Acute leukemia in infants. Curr. Oncol. Rep. 23:27.

Kerschensteiner, M., Gallmeier, E., Behrens, L., Leal, V. V., Misgeld, T., Klinkert, W. E., et al. (1999). Activated human T cells, B cells, and monocytes produce brain-derived neurotrophic factor in vitro and in inflammatory brain lesions: a neuroprotective role of inflammation? J. Exp. Med. 189, 865-870. doi: 10.1084/ jem.189.5.865

Laszlo, G. S., Alonzo, T. A., Gudgeon, C. J., Harrington, K. H., Kentsis, A., Gerbing, R. B., et al. (2015). High expression of myocyte enhancer factor 2C (MEF2C) is associated with adverse-risk features and poor outcome in pediatric acute myeloid leukemia: a report from the Children's Oncology Group. J. Hematol. Oncol. 8:115.

Luo, H., Qin, Y., Reu, F., Ye, S., Dai, Y., Huang, J., et al. (2016). Microarray-based analysis and clinical validation identify ubiquitin-conjugating enzyme E2E1 (UBE2E1) as a prognostic factor in acute myeloid leukemia. J. Hematol. Oncol. 9:125.

Malard, F., and Mohty, M. (2020). Acute lymphoblastic leukaemia. Lancet 395, 1146-1162.

Mattioli, F., Hayot, G., Drouot, N., Isidor, B., Courraud, J., Hinckelmann, M. V., et al. (2020). De Novo frameshift variants in the neuronal splicing factor NOVA2 result in a common C-Terminal extension and cause a severe form of neurodevelopmental disorder. Am. J. Hum. Genet. 106, 438-452.

Mochizuki, S., and Okada, Y. (2007). ADAMs in cancer cell proliferation and progression. Cancer Sci. 98, 621-628. doi: 10.1111/j.1349-7006.2007. 00434.x

Pasterkamp, R. J., Peschon, J. J., Spriggs, M. K., and Kolodkin, A. L. (2003). Semaphorin 7A promotes axon outgrowth through integrins and MAPKs. Nature 424, 398-405. doi: 10.1038/nature01790
Pastorczak, A., Domka, K., Fidyt, K., Poprzeczko, M., and Firczuk, M. (2021). Mechanisms of immune evasion in acute lymphoblastic leukemia. Cancers 13:1536. doi: $10.3390 /$ cancers 13071536

Rank, C. U., Wolthers, B. O., Grell, K., Albertsen, B. K., Frandsen, T. L., Overgaard, U. M., et al. (2019). Asparaginase-associated pancreatitis in acute lymphoblastic leukemia: results from the NOPHO ALL2008 treatment of patients 1-45 Years of Age. J. Clin. Oncol. 38, 145-154. doi: 10.1200/jco.19.02208

Saito, Y., Miranda-Rottmann, S., Ruggiu, M., Park, C. Y., Fak, J. J., Zhong, R., et al. (2016). NOVA2-mediated RNA regulation is required for axonal pathfinding during development. eLife 5:e14371.

Sato, Y., and Takahashi, H. (1998). Molecular cloning and expression of murine homologue of semaphorin K1 gene. Biochim. Biophys. Acta 1443, 419-422. doi: 10.1016/s0167-4781(98)00245-0

Schwab, C. J., Chilton, L., Morrison, H., Jones, L., Al-Shehhi, H., Erhorn, A., et al. (2013). Genes commonly deleted in childhood B-cell precursor acute lymphoblastic leukemia: association with cytogenetics and clinical features. Haematologica 98, 1081-1088. doi: 10.3324/haematol.2013.085175

Siegel, R. L., Miller, K. D., and Jemal, A. (2016). Cancer statistics, 2016. CA A Cancer J. Clin. 66, 7-30. doi: 10.3322/caac.21332

Starý, J., and Hrušák, O. (2016). Recent advances in the management of pediatric acute lymphoblastic leukemia. F1000Res. 5:2635.

Uren, R. T., and Turnley, A. M. (2014). Regulation of neurotrophin receptor (Trk) signaling: suppressor of cytokine signaling 2 (SOCS2) is a new player. Front. Mol. Neurosci. 7:39. doi: 10.3389/fnmol.2014.00039

Ward, E., DeSantis, C., Robbins, A., Kohler, B., and Jemal, A. (2014). Childhood and adolescent cancer statistics, 2014. CA Cancer J. Clin. 64, 83-103.

Weber, S., and Saftig, P. (2012). Ectodomain shedding and ADAMs in development. Development 139, 3693-3709. doi: 10.1242/dev.076398

Wei, J., Xie, Q., Liu, X., Wan, C., Wu, W., Fang, K., et al. (2020). Identification the prognostic value of glutathione peroxidases expression levels in acute myeloid leukemia. Ann. Transl. Med. 8:678. doi: 10.21037/atm-20-3296

Wolfsberg, T. G., Straight, P. D., Gerena, R. L., Huovila, A. P., Primakoff, P., Myles, D. G., et al. (1995). ADAM, a widely distributed and developmentally regulated gene family encoding membrane proteins with a disintegrin and metalloprotease domain. Dev. Biol. 169, 378-383. doi: 10.1006/dbio.1995.1152

Wolthers, B. O., Frandsen, T. L., Patel, C. J., Abaji, R., Attarbaschi, A., Barzilai, S., et al. (2019). Trypsin-encoding PRSS1-PRSS2 variations influence the risk of asparaginase-associated pancreatitis in children with acute lymphoblastic leukemia: a Ponte di Legno toxicity working group report. Haematologica 104, 556-563. doi: 10.3324/haematol.2018.199356

Yang, H., Zhang, J., Li, J., Zhao, F., Shen, Y., and Xing, X. (2018). Overexpression of miR-574-3p suppresses proliferation and induces apoptosis of chronic myeloid leukemia cells via targeting IL6/JAK/STAT3 pathway. Exp. Ther. Med. 16, 4296-4302.

Yang, Y. Y., Yin, G. L., and Darnell, R. B. (1998). The neuronal RNA-binding protein Nova-2 is implicated as the autoantigen targeted in POMA patients with dementia. Proc. Natl. Acad. Sci. U.S.A. 95, 13254-13259. doi: 10.1073/pnas.95. 22.13254

Yazdani, U., and Terman, J. R. (2006). The semaphorins. Genome Biol. 7:211.

Yuzugullu, H., Von, T., Thorpe, L. M., Walker, S. R., Roberts, T. M., Frank, D. A., et al. (2016). NTRK2 activation cooperates with PTEN deficiency in T-ALL through activation of both the PI3K-AKT and JAK-STAT3 pathways. Cell Discov. 2:16030.

Zapata-Tarrés, M., Balandrán, J. C., Rivera-Luna, R., and Pelayo, R. (2021). Childhood acute leukemias in developing nations: successes and challenges. Curr. Oncol. Rep. 23:56.

Zhou, Y., You, M. J., Young, K. H., Lin, P., Lu, G., Medeiros, L. J., et al. (2012). Advances in the molecular pathobiology of B-lymphoblastic leukemia. Hum. Pathol. 43, 1347-1362. doi: 10.1016/j.humpath.2012.02.004

Conflict of Interest: The authors declare that the research was conducted in the absence of any commercial or financial relationships that could be construed as a potential conflict of interest.

Copyright () 2021 Alsuwaidi, Hachim and Senok. This is an open-access article distributed under the terms of the Creative Commons Attribution License (CC BY). The use, distribution or reproduction in other forums is permitted, provided the original author(s) and the copyright owner(s) are credited and that the original publication in this journal is cited, in accordance with accepted academic practice. No use, distribution or reproduction is permitted which does not comply with these terms. 